\title{
Developing an Advanced Module for Back-Contact Solar Cells
}

\author{
Jonathan Govaerts, Jo Robbelein, Mario Gonzalez, Ivan Gordon, Kris Baert, \\ Ingrid De Wolf, Senior Member, IEEE, Frederick Bossuyt, Steven Van Put, \\ and Jan Vanfleteren, Member, IEEE
}

\begin{abstract}
This paper proposes a novel concept for integrating ultrathin solar cells into modules. It is conceived as a method for fabricating solar panels starting from back-contact crystalline silicon solar cells. However, compared to the current state of the art in module manufacturing for back-contact solar cells, this novel concept aims at improvements in performance, reliability, and cost through the use of an alternative encapsulant, namely silicones as opposed to ethylene vinyl acetate, an alternative deposition technology, being wet coating as opposed to dry lamination; and alternative module-level metallization techniques, as opposed to cell-level tabbing-stringing or conductive foil interconnects. The process flow is proposed, and the materials and fabrication technologies are discussed. As the durability of the module, translated into the module's lifetime, is very important in the targeted application, namely solar cell modules, modeling and reliability testing results and considerations are presented to illustrate how the experimental development process may be guided by experience and theoretical derivations. Finally, feasibility is demonstrated in some first proofs of the concept, and an outlook is given pointing out the direction for further research.
\end{abstract}

Index Terms - Embedding, solar modules, thin cells.

\section{INTRODUCTION}

$\mathbf{U}$ P UNTIL now, and probably for still some time to come, crystalline silicon solar cells are and will be the most prevalent type of photovoltaic technologies around, accounting for over $90 \%$ of the electricity generated by solar energy worldwide. Motivated by the prospect of a clean, renewable, unlimited - or rather, nondepleting for the foreseeable future and beyond-and independent supply of energy, government and private incentives alike have a significant impact in bringing solar electricity within the reach of the general public in the developed world. However, to further lower the price

Manuscript received March 19, 2010; revised June 2, 2011; accepted June 13, 2011. Date of publication September 6, 2011; date of current version September 21, 2011. Recommended for publication by Associate Editor T.-C. Chiu upon evaluation of reviewers' comments.

J. Govaerts, J. Robbelein, M. Gonzalez, I. Gordon, and K. Baert are with imec, Leuven 3001, Belgium (e-mail: jonathan.govaerts@gmail.com; jo.robbelein@imec.be; mario.gonzalez@imec.be; ivan.gordon@imec.be; kris. baert@imec.be).

I. De Wolf is with imec, Leuven 3001, Belgium. He is also with the Department of Metallurgy and Materials Engineering, Katholieke Universiteit Leuven, Leuven 3001, Belgium (e-mail: ingrid.dewolf@imec.be).

F. Bossuyt, S. Van Put, and J. Vanfleteren are with imec, Leuven 3001, Belgium. They are also with the Department of Electronics and Information Systems, Universiteit Ghent, Ghent 9000, Belgium (e-mail: frederick.bossuyt@elis.ugent.be.be; svanput@intec.ugent.be; jan.vanfleteren@elis.ugent.be).

Color versions of one or more of the figures in this paper are available online at http://ieeexplore.ieee.org.

Digital Object Identifier 10.1109/TCPMT.2011.2161082 of solar electricity, and to make it available to an even wider public, e.g., in the developing nations as well, it is important that the production cost is still substantially lowered. In the long run, thin-film, and organic photovoltaics (PVs) seem very promising in this respect, but on a shorter term, and for higherefficiency applications, lowering the price of crystalline silicon solar panels is very much desirable.

There are of course a number of ways to tackle this issue, ranging from lower temperature processing and cheaper materials to higher throughput systems and improved efficiencies. Here, the idea is to embark on the widely followed route of evolution toward ever thinner cells. This serves the purpose of cutting cost by reducing the amount of silicon needed, but it could also be beneficial in minimizing possible future issues with the supply of solar-grade silicon [1].

The conventional approach for manufacturing modules widely adopted for modules based on front- and backcontacted cells is, e.g., described in [2]. This technology is very mature but was developed for cells requiring out-ofplane interconnection between the front of one cell and back of the neighboring cell. When considering back-contact cells however, it is worth questioning whether such a technology is still optimal and preferable. For reference, a range of types of crystalline silicon back-contact solar cells and their link with conventional cells, as well as a comparison between conventional modules and adapted module manufacturing based on back-contact solar cells, are given in [3].

The current state of the art in back-contact module manufacturing (up to now, conventions are still too much lacking in this field to speak of a "conventional" approach) is exemplified by the approaches put forward by, e.g., SunPower [4], Energy Research Centre of the Netherlands [5], the Schott-Solland collaboration [6], and Advent Solar-Applied Materials [7], also Photovoltech and Bosch have already shown demonstration modules with similar technology. Broadly, they can be classified into two categories: conventional module technology and monolithic module assembly (MMA), shown in Fig. 1. Both approaches are based on assembly using dry lamination with ethylene vinyl acetate (EVA), whereas for interconnection the conventional approach uses a tabbing/stringing process, and monolithic module assembly encompasses a modulelevel interconnection technique based on conductive foils and adhesives. (The Schott-Solland approach could be considered a hybrid, as the module is first laminated, and then the ribbons are laser-soldered to the cells through the laminated layers, and therefore referred to as in-laminate laser soldering). 


\begin{tabular}{|c|c|c|c|c|}
\hline & \multicolumn{2}{|c|}{ State-of-the-art } & \multirow{2}{*}{$\begin{array}{l}\text { imec } \\
\text { i-module }\end{array}$} & \multirow{2}{*}{$\begin{array}{l}\text { Potentional } \\
\text { advantages }\end{array}$} \\
\hline & Conventional & MMA & & \\
\hline $\begin{array}{l}\text { Assembly } \\
\text { process }\end{array}$ & Dry lamination & Dry lamination & Wet coating & $\begin{array}{l}\text { - Speed, throughput } \\
\text { - Thin cell capability }\end{array}$ \\
\hline $\begin{array}{l}\text { Assembly } \\
\text { material }\end{array}$ & EVA foils & EVA foils & Silicones & $\begin{array}{l}\text { - Optical perfamance } \\
\text { - Reliability }\end{array}$ \\
\hline Interconnection & $\begin{array}{l}\text { Standalone cell-to- } \\
\text { cell soldering } \\
\text { (tabbing/stringing) }\end{array}$ & $\begin{array}{l}\text { Module-level } \\
\text { interconnection } \\
\text { (conductive foil } \\
\text { and adhesives) }\end{array}$ & $\begin{array}{l}\text { Module-level } \\
\text { interconnection } \\
\text { (soldering, } \\
\text { plating) }\end{array}$ & $\begin{array}{l}\text { - Reduced cell-level } \\
\text { handling/processing } \\
\text { - Thin cell capability } \\
\text { - speed, throughput }\end{array}$ \\
\hline
\end{tabular}

Fig. 1. Imec's proposed i-module concept versus the current state-of-the-art approaches for manufacturing of modules based on back-contact solar cells.

Several potential improvements to these approaches can be conceived. Wet coating as opposed to dry lamination could result in increased speed and throughput and allow for thinner cells as any uneven pressure distribution during lamination could result in breakage.

The use of silicones as adhesive and encapsulant instead of EVA is considered to be beneficial in terms of optical performance [8], [9], due to reduced ultraviolet (UV) light absorption, and reliability [9], [10], because of lower glass transition temperature and Young's modulus, better UV stability, and reduced moisture take-up and higher heat and flame resistance, the latter being interesting from, respectively, the processing (e.g., the silicone can withstand soldering temperatures) and safety points of view. Specifically for PV module packaging, where a high transparency of the front sheet and encapsulants throughout its functional life is required, the significant UV exposure to solar radiation can be detrimental to some polymer encapsulants. The so-called yellowing and browning of EVA is not an issue for silicones, as they are essentially UV-transparent and therefore inherently UV-stable [9], [11]. For PV modules, also heat (dissipation) issues are important, as a higher temperature negatively affects the cell performance. The thermal conductivity of silicones, e.g., the back encapsulation in the case of the i-module concept, is similar to that of EVA and can be tuned through the use of thermally conductive fillers. This has already been demonstrated for applications where thermal management is critical, e.g., in packaging for microelectronics and heaters [9], [12]. To be complete, it should be noted that this is also an option for EVA, as elaborated in [13].

For the module-level interconnection, potential benefits are the elimination of the stringing and string handling, as well as increased throughput, as the interconnection does no longer need to be a sequential process but instead can be realized by applying a patterned metallization across the complete module simultaneously, which is also the case for the MMA approach obviously, while the cells are fully supported by and fixed to the glass substrate, which is not the case for the MMA approach. Additionally, the availability of the backside of the cells, while fixed to the glass, together with the chemical resistance of the silicone, could allow direct plating of the interconnect pattern on the module. This would eliminate the use of glued or soldered contacts, resulting in a reduced number of contact interfaces and the associated issues of adhesion and contact resistance. In a later stage, the plating of the interconnect metallization could even be combined with the cell metallization, significantly reducing the amount of process steps (although increasing the complexity and

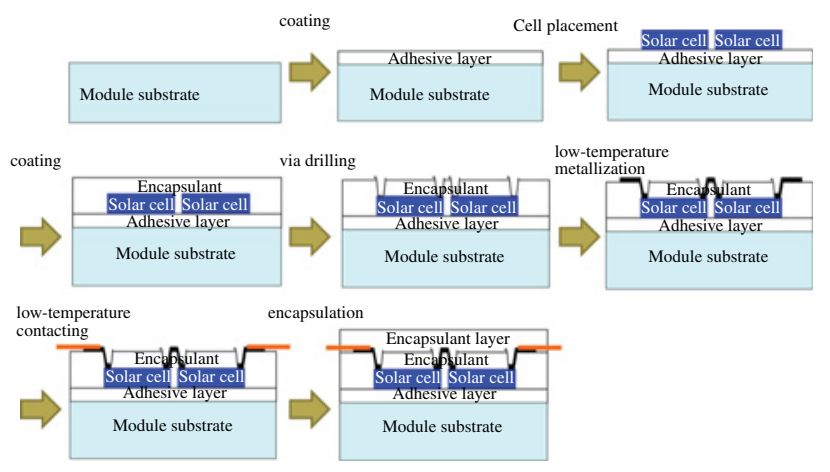

Fig. 2. Process flow of the i-module technology.

requirements for this metallization step). Finally, the reduced cell-level handling and processing means that the concept could be applied to fabricate modules with ultrathin solar cells-well below $100 \mu \mathrm{m}$ assuming they can be fabricatedthat are otherwise very difficult to integrate into modules with conventional methods, as these are very fragile.

\section{TeChNology Flow}

The concept called the i-module (for interconnect module) is a novel method for fabricating solar panels starting from backcontact crystalline silicon solar cells. In the layer buildup, it is somewhat similar to the MMA approach described in [7] but, as pointed out, it differs substantially in the types of encapsulant materials, processing technologies, and layer assembly and metallization scheme. Fig. 2 gives an overview of the conceived process flow.

Starting from a clean glass module substrate, an adhesive layer is first applied. As the sun's rays will be passing through the glass and the adhesive layer, both should be transparent and matched to minimize reflection. The deposition can be done by coating techniques such as blade coating, spray coating, knife-over-roll coating, and dip coating, or printing techniques as screenprinting, dispensing, and gravure printing. Another possibility might be lamination.

The next step is the placement of the fully processed solar cell, which is done with the front side toward the glass, so that the contacts remain available at the backside. An important remark here is that, in case of an ultrathin cell, care must be taken so as not to break the fragile cell at this stage. Additionally, any air entrapment in between the cell and the substrate has to be avoided, as the resulting scattering of light and unmatched interfaces reduce the amount of energy that can reach the front side of the cell [14]. Also, the inclusion of air bubbles could be detrimental from a reliability point of view, as these could turn out to be preferential locations for delamination or accumulation of moisture, possibly resulting in accelerated corrosion. This may be achieved in several ways, e.g., by applying vacuum during or after placement, or through non-parallel placement of the cells, e.g., by preflexing the cell prior to placement so that any air is gradually driven out as the cell is lowered. After this, the cells are covered by depositing an encapsulant, possibly with the same techniques as used for depositing the adhesive layer earlier in the flow. Depending on 
the technique, it may be possible to deposit the encapsulant in a pattern, e.g., through screen printing or dispensing, leaving the cells' contacts uncovered.

Now the cells are embedded, but obviously they still have to be interconnected and contacted to bring out the generated current. In case the encapsulant is covering everything, openings to the contacts are needed and can be realized by drilling vias through the encapsulant material, e.g., with a laser. In case the encapsulant is deposited in a pattern, this is obviously not needed. Subsequently, a metal layer is deposited, with a pattern according to the preferred interconnection scheme for the cells. The metallization can be achieved by several low-temperature processes, e.g., thin-film techniques such as evaporation and sputtering, or printing techniques such as as screenprinting, or aerosol/inkjet printing of a seed layer followed by plating. Outside contacts should be provided, e.g., by soldering, gluing, or welding strings to the designated areas of the metallization. Finally, another layer of encapsulant, possibly with a back sheet, is applied to protect the metallization against corrosion and reinforce the relatively weak interconnection points.

\section{Materials AND FABRication Technologies}

In the previous paragraphs, a very general description of the process flow was given to leave open as many possibilities as possible regarding materials and sizes so as not to limit the exploitation of such a technology. Module substrates have to be transparent and offer protection against outside influences (hail and gravel impact, UV, acidic rain, dirt, and cleaning agents) and constitute the backbone of the module. Other than these, the size $\left(1-50000 \mathrm{~cm}^{2}\right)$, thickness $(100-5000 \mu \mathrm{m})$, and material (glass, plastic, etc.) may differ greatly. The adhesive layer should be transparent, preferably have a refractive index in between that of the substrate and the cell surface, matching the interfaces as much as possible, and show good adhesion to the substrate as well as the cell. Regarding the cells, fully finished back-contact solar cells are used. They may vary in shape (square, semisquare, rectangular, circular), area $\left(1-225 \mathrm{~cm}^{2}\right)$, thickness $(5-1000 \mu \mathrm{m})$, and material $(\mathrm{Si}, \mathrm{Ge}$, GaAs, etc.). The encapsulant has to adhere well to the cell, to the adhesive layer, and to the metallization, and has the primary function of protecting the whole assembly against the environment, mainly moisture and thermally induced stresses. Considering that modules heat up significantly when exposed to the sun, and that the embedded cells typically perform better at lower temperatures, it could also act as a good thermal conductor to the environment. From this view, a high thermal conductivity would be beneficial. Finally, the used metallization has to provide low contact resistance, exhibit good adhesion to the encapsulant, have sufficient currentcarrying capabilities as well as low resistivity to minimize voltage losses and joule heating.

In the following paragraphs, some specific materials and fabrication technologies have been chosen and elaborated to develop the process flow as described. As substrates, glass of varying thickness has been used, ranging from 0.7 to $3.3 \mathrm{~mm}$.

Adhesive and encapsulant layers are both silicone layers, "PV6010 Cell Encapsulant," supplied by Dow Corning. This

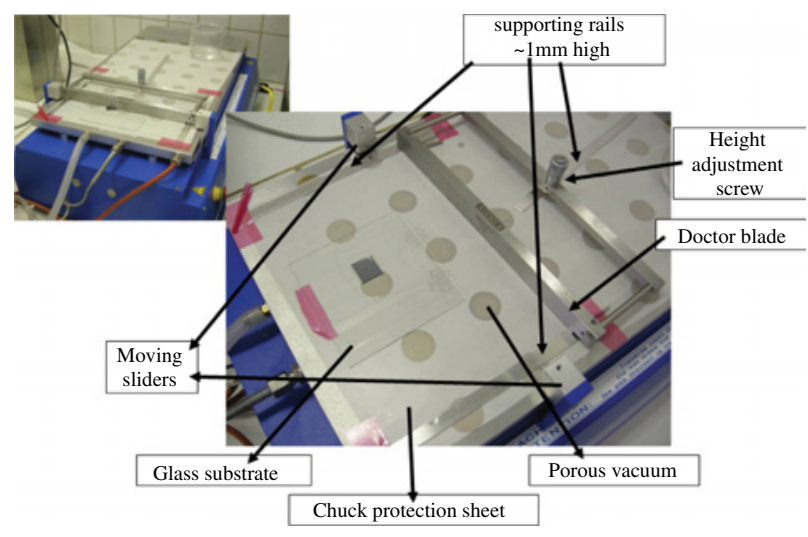

Fig. 3. Used blade coating setup.

two-component material is selected for its high transparency in combination with a low value for the product of the Young's modulus and coefficient of thermal expansion $(\mathrm{E} \times \mathrm{CTE})$, which is beneficial for low-stress embedding, and a high dielectric strength. It also features very good self-priming adhesion and humidity resistance. More information on the advantages of using silicones over standard encapsulants such as EVA for PV modules can be found in [8]-[10], [15], and [16]. In short, the main advantages of silicones are transparency, expected improved reliability, and liquid processing possibilities. The main drawbacks at this moment are cost of the basic material and the fact that it is a new material in the field of module manufacturing. In [17] is given an example which illustrates that alternatives for EVA are indeed being considered and developed across the market. Coating of these silicone layers onto the substrates is done by blade coating with a lab tool that is also commonly used for the evaluation of paints-the so-called film applicator. Typically, the blade gap of the casting knife can be set by microscrews with an accuracy of $1 \mu \mathrm{m}$. Thickness control of the coated layer is obviously important and, in this respect, it is worth mentioning that the final thickness will depend on the wet film thickness-depending on the mass loss during curing - which is in turn correlated to the blade gap height setting. These correlations are of course different for different materialsviscosity, cohesion, and adhesion, etc. The blade coating setup is illustrated in Fig. 3.

Cells that have been used in the described experiments range from small square $\left(4 \mathrm{~cm}^{2}\right)$ to large semisquare $\left(150 \mathrm{~cm}^{2}\right)$, with a thickness around $120 \mu \mathrm{m}$. Both dummy silicon samples as well as fully finished back-contact silicon solar cells are used. Placement can be done manually, but care has to be taken to avoid the inclusion of air bubbles in between the cell and the substrate, as stated in the previous section. Such air bubbles can be avoided or minimized through the use of a vacuum vacuum environment, as shown in Fig. 4.

As the silicone in which the cells are placed is still wet during and after placement, the cells can still move after placement. This is in some ways an advantage, e.g., to correct the alignment if necessary, but there is also a drawback, the cells can still move when the silicone is subsequently cured. This is more of an engineering problem and may be solved by using a more automated system for placing and curing. Curing can be 


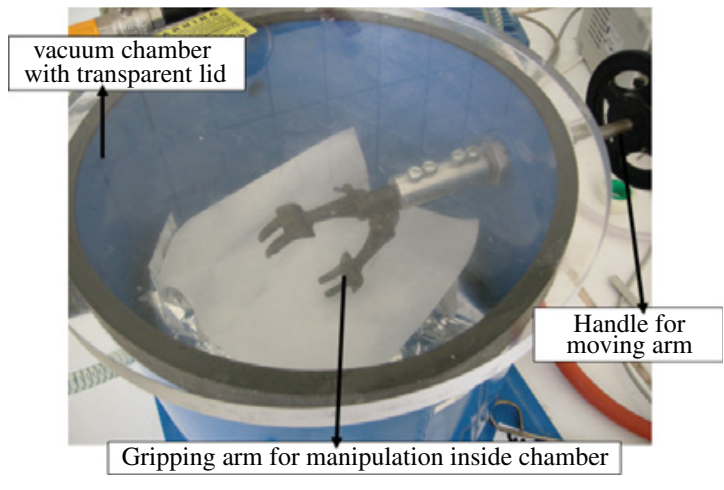

Fig. 4. Used vacuum placement setup.

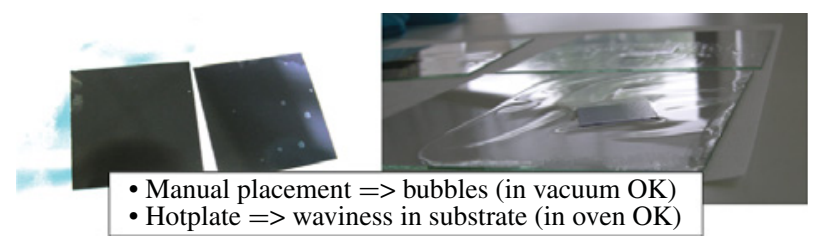

Fig. 5. Encountered placement and curing phenomena.

done on a hotplate or in an oven, but it was observed that using a hotplate results in some waviness of the resulting surface, which is not present in oven-cured samples. This can probably be attributed to a difference in heat distribution uniformity. These encountered phenomena are illustrated in Fig. 5.

Drilling vias to the cells can be done with a laser setup. Selective laser processing of layers in a multilayer stack is very well possible, but it gets more sophisticated (laser wavelength, power density, exposure duration etc.) with increasing complexity of the stack (absorption spectrum and composition of the different layers, heat conduction, etc.), as, e.g., indicated in [18]. Here, the used tool incorporates a moving stage with an accuracy of $1 \mu \mathrm{m}$, and three fixed lasers, $\mathrm{CO}_{2}, \mathrm{YAG}$, and excimer, with camera alignment. The whole setup, except for the power setting, is software-controlled. Designs can be loaded and the settings applied, and, after aligning, the process runs automatically. This technology of laser ablation for contacting embedded cells has already proven its attractiveness for other applications as shown in [19]. For the i-module application of drilling vias through silicone to the metal contacts of the cell, however, there is a slight difference, as the silicone is (and should be as much as possible) very much transparent for the 355-nm wavelength of the YAG laser. Therefore, a $\mathrm{CO}_{2}$ laser operating at a wavelength in the deep infrared (around $10 \mu \mathrm{m}$ ) is preferable, as silicone has absorption peaks in the infrared region that could be exploited to this end-an attractive option is described in [20] - as it stops on metal and has no difficulties in ablating silicone. The setup with the used $\mathrm{CO}_{2}$ laser is shown in Fig. 6 .

Depending on the application (thickness and type of material to be drilled), laser ablation can be optimized through attenuation, number of pulses, masks, as well as frequency, and power settings. Some pictures of laser-ablated vias are shown in Fig. 7.

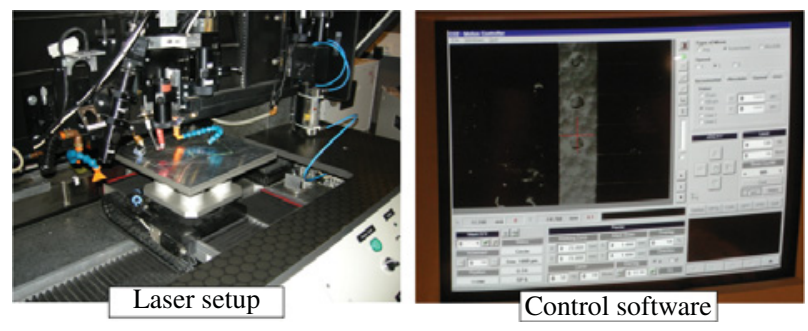

Fig. 6. Used laser system setup.

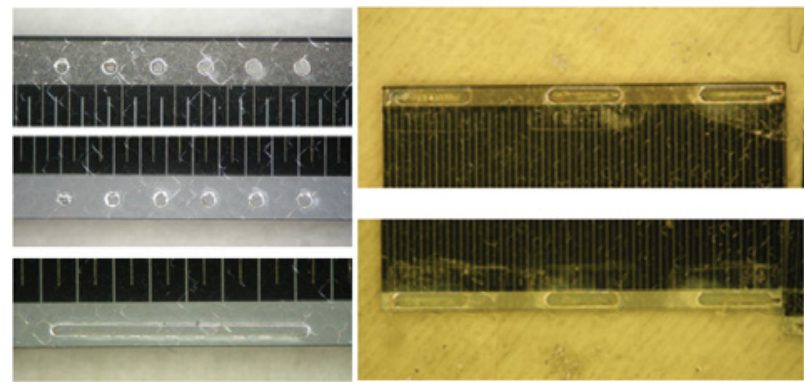

Fig. 7. Example of laser tuning by varying the number of laser pulses to optimize the laser drilled vias (top left); possibility for ablating lines in the silicone encapsulant (bottom left); and spot size adjusted to fit the 1-mm-wide busbars of the solar cells.

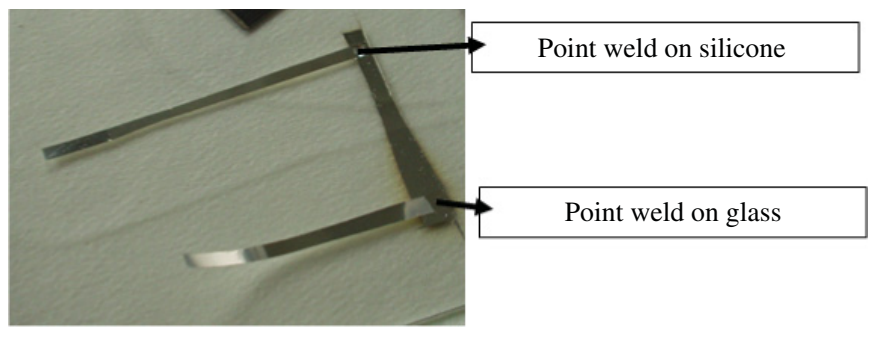

Fig. 8. Experiments for welding on top of glass and silicone.

For metallization, several options were tested. Trials were carried out using evaporation through a shadowmask to deposit patterned stacks of $\mathrm{Ti} / \mathrm{Pd} / \mathrm{Ag}$ and $\mathrm{Al}$, which are common metallizations for back-contact solar cells. Next to this, a lowtemperature-curable Ag paste from DuPont, "Solamet PV410," was tested for screenprinting applications. Evaporation and screenprinting are rather standard technologies in crystalline silicon solar cell processing, in the lab and industrial solar cell production environments, respectively, and therefore they are not elaborated here.

Regarding contact welding, this was done to connect the Ag film or tabbing strings-which are usually Sn-coated $\mathrm{Cu}$ strings - to the metallization and bring out the contacts. A very basic setup was used in which the applied force and electrical discharge profile could be defined. Fig. 8 shows some trials for contact-welding $\mathrm{Ag}$ film stripes to an evaporated $\mathrm{Ti} / \mathrm{Pd} / \mathrm{Ag}$ line on glass and silicone.

\section{Modeling And Reliability}

Concerning reliability, the first steps have been taken toward predicting the likely and less likely failures in modules based on i-module technology. This is typically done in the so-called 


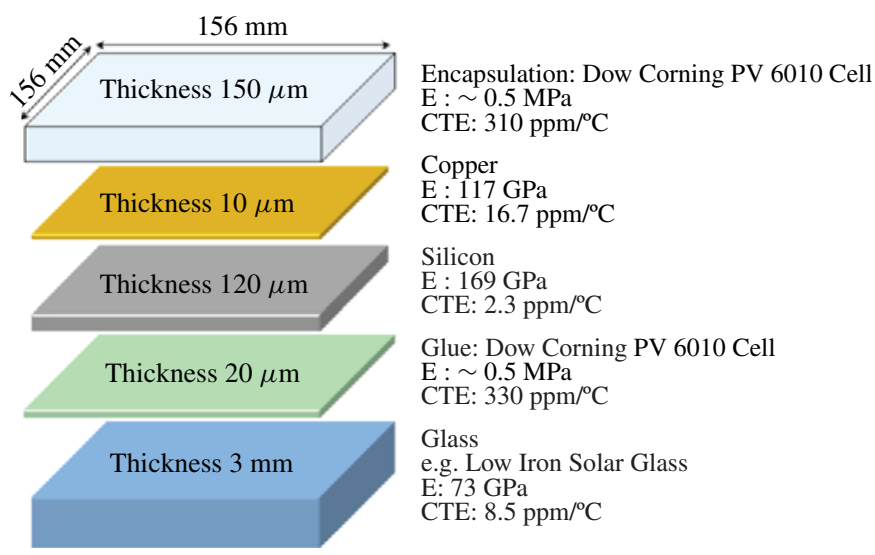

Fig. 9. Basic layer buildup model of the module indicating the geometry and material properties.

failure mode and effect analysis (FMEA). This is a list of failure modes, linked to their respective causes, mechanisms, and consequences. Then, a risk priority number is attributed to each of the modes, indicating the relative importance of each mode. Additionally, relevant testing schemes can be set up, in accordance with the different failure modes (failuredriven testing), and/or the industry standards (applicationdriven testing, which usually is a requirement for market acceptance). To round up the FMEA, the list includes the kind of samples to be tested as well as the means of inspection after testing. Based on the FMEA, the potential failures are related to the cracking of the cells, cracking of the interconnections, and delamination of the silicone layers.

In order to better understand the mechanisms behind such failures, simulations of a module model can be very helpful. By using finite element modeling (FEM), stresses, and strains in the different layers may be predicted. With these results, it is possible to make a quantitative comparison of the different problematic areas in the module. For initial modeling, the different layers, shown in Fig. 9, have been simulated to extract the stresses and strains of each material. The nominal dimensions and the material properties used in the model are indicated in Fig. 9. Stresses were induced in the system by cooling down the structure from $80{ }^{\circ} \mathrm{C}$, which is the curing temperature of the used silicone encapsulant, to $-40{ }^{\circ} \mathrm{C}$, which is the minimal temperature in a thermal cycle fatigue test used in PV module qualification standards per IEC61215.

The thermomechanical behavior of the module was simulated by using 3-D FEM. The commercial code MSC.MARC was used for this purpose. Due to the square geometry of the integrated module, by applying the correct boundary conditions only one-eighth of the module needs to be modeled.

Simulated with the nominal values for the layers as in Fig. 9, the silicon is stressed compressively, with maximum values in the center of the cell as illustrated in Fig. 10(a). The compressive strength of silicon is typically above $1 \mathrm{GPa}$, therefore the cells should be in the safe zone with regard to cracking issues.

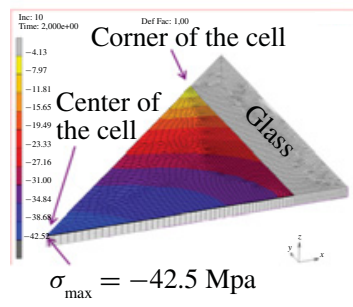

(a)

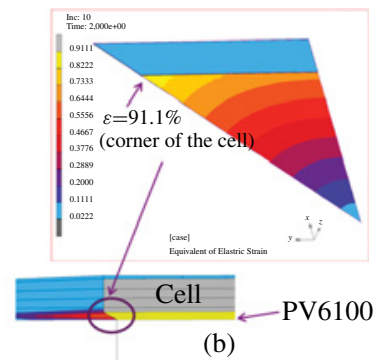

Glass
Fig. 10. 3-D FEM results. (a) Maximum principal stress in the silicon cell. (b) Equivalent elastic strain in the glue layer.

Another result of this modeling is shown in Fig. 10(b) where high strains in the silicone, in the order of $90 \%$, are calculated. Depending on the adhesion strength of the silicone, this relatively high deformation may lead to delamination at the sides, especially in view of the thermal cycling that any module will be subjected to during its lifetime. The adhesion strength of the silicone used for this paper has not been characterized yet and, therefore, it is not possible to conclude whether a failure might occur. However, it is important to keep this value as small as possible.

The FMEA and simulations are obviously theoretical tools to maximize the chances of success and to make sure everything is considered beforehand. Of course, the actual reliability testing will have to be done afterwards to check the viability of the developed technology and adjust and optimize the processing where necessary.

Based on all the thus gained knowledge on the reliability of the process and the resulting modules, an aging model can be defined afterwards and the module lifetime may be predicted. Of course, the idea is to predict the module's lifetime in a real environment and therefore it is still relevant to keep track of the performance of modules during and after outdoor exposure. An example of such an evaluation is given in [21]. This article already gives an indication of the improved reliability of modules with silicone encapsulation, although it is difficult to rule out other differences between the different module types that might also be contributing significantly in the comparison.

\section{RESULTS}

The i-module concept flow has been developed, at first with dummy cells and several trials, and has already been demonstrated as a proof of concept with functional cells. The type of cells used for the first trials are interdigitated backcontact solar cells, with specifications as shown in Fig. 11, some more information on these cells can be found in [22].

Laser drilling was optimized to suit the $900-\mu \mathrm{m}$ wide busbars of the cells as illustrated in Fig. 7.

The module was then metallized with a low-temperature $\mathrm{Ag}$ paste by means of manual screenprinting through a $25-\mu \mathrm{m}$ polyimide (PI) shadowmask. The resulting i-module and measurements are shown in Fig. 12.

These results are still preliminary, considering these are only the first ones, but very much confirm the functionality. The loss in current can largely be attributed to the transmission 


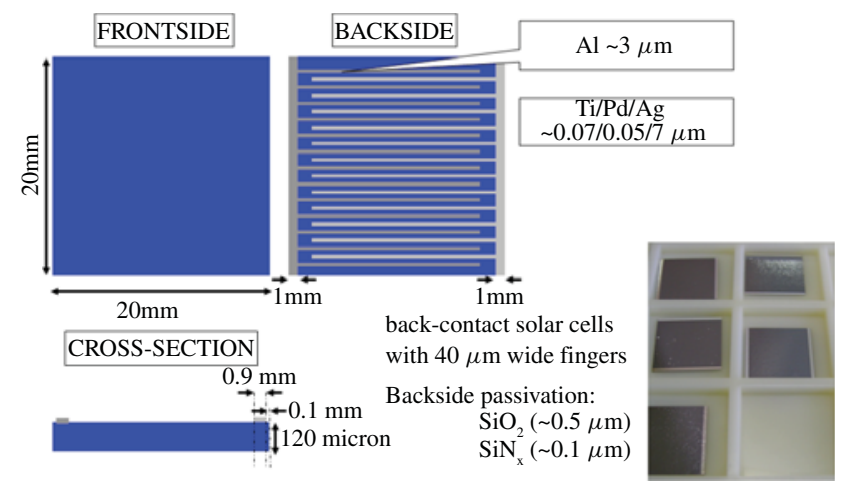

Fig. 11. Specifications of the used back-contact solar cells.

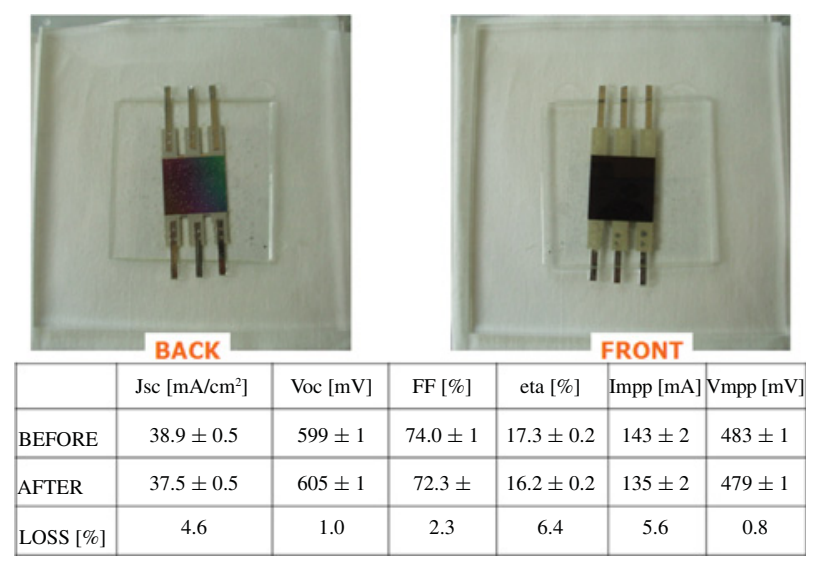

Fig. 12. Results of the functional cell BSF1C31 embedded in silicone on glass following the i-module flow.

loss of light due to the combined glass and encapsulant sandwich, as opposed to the bare cell. This is in fact mainly determined by the reflection from (and to a lesser extent absorption in) the front glass surface of the module, in the case of thin encapsulant layers as explained in [16], where the transmission of light from outside of the module up to the cell interface is typically $95 \%$ or lower. This is reflected in a drop in the amount of light entering the cell and, therefore, a drop in generated current. The loss in fill factor is most probably due to additional series resistance coming from the low-temperature paste: similar measurements later on (although with a different type and size of sample) confirmed that, e.g., an increase in interconnection resistance-so series resistance-of $3 \mathrm{~m} \Omega$ (this value is theoretically derived from string interconnection; in the I-V measurements this appears as an increase from 2100 to $2200 \mathrm{~m} \Omega . \mathrm{cm}^{2}$ ) results in a reduction in the FF of $\sim 0.5 \%$. Considering that the low-temperature paste used for interconnection here has a relatively high series resistance of $18 \mathrm{~m} \Omega / \mathrm{sq}$ (at $25 \mu \mathrm{m}$ thickness), this is a likely explanation for the 2-3\% loss in FF. The small increase in $\mathrm{V}_{o c}$ may be due to a slight difference in temperature during the measurement. Such losses for module-encapsulated cells as compared to standalone cells are similar to those reported elsewhere, e.g., in [23] 4-5\% efficiency losses were reported. In our case, the glass had no antireflection coating and the metallization and contacting still need to be optimized. An important remark also concerns the fact that the used



Fig. 13. I-Module demonstrating four cells connected in series.

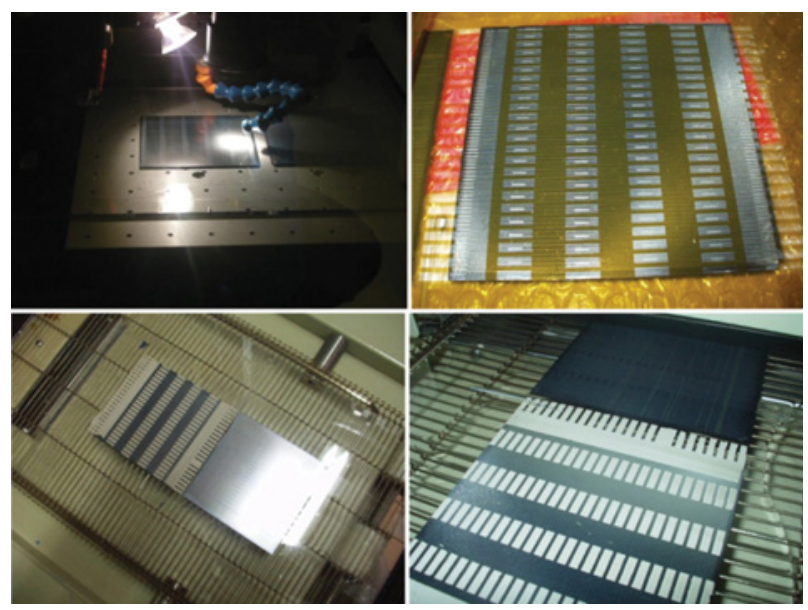

Fig. 14. First upscaling experiments: laser drilling (top left), shadowmask application (top right), and curing of metallization in belt dryer (bottom).

setup for measuring the cell/module performance is geared toward and calibrated for measuring large-area conventional crystalline silicon solar cells (i.e., two-side contacted cells), so that measurement errors for the presented measurements cannot easily be extrapolated from the well-determined known measurement errors of the system. This is something that is still under investigation.

The following trials were carried out to similarly demonstrate the proof of concept of the optimistically called "minimodules" integrating multiple cells using the same technology. Some pictures of the resulting samples are shown in Fig. 13. Performance measurements, being in the same range, confirmed the previous results shown in Fig. 12 (of course keeping in mind the same remark as above on measurement errors).

In the next stages, the flow still needs considerable development and optimizations before it can be considered an industrially viable process, not only in terms of process control, reproducibility, and throughput. One topic is, of course, scaling the size of the cells, and in this area the first attempts are being made to embed $100 \mathrm{~mm}$ by $100 \mathrm{~mm}$ cells, as shown in Fig. 14 .

Scaling down the thickness of the cells is another topic that is being investigated, and in this area, dummy silicon of $45 \mu \mathrm{m}$ thick has been embedded to show the proof of the concept. 


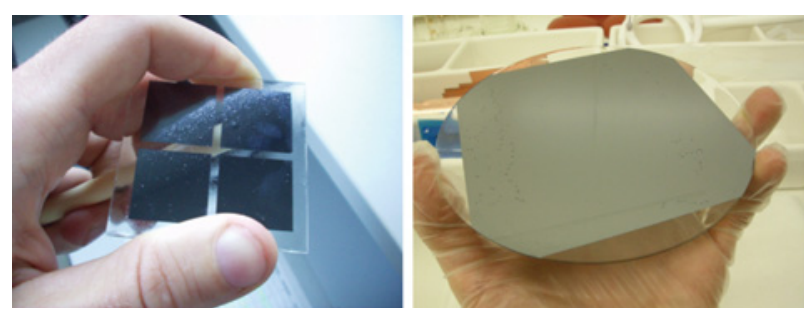

Fig. 15. Small (left) and large (right) $45-\mu \mathrm{m}$ thick silicon embedded in silicone.

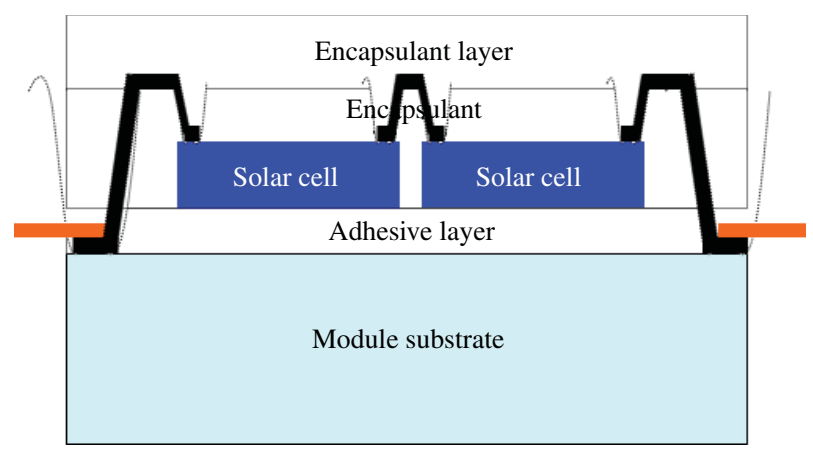

Fig. 16. Alternative schematic with welds on the glass substrate i.o. on top of the silicone.

This is illustrated in Fig. 15, both for small $20 \mathrm{~mm}$ by $20 \mathrm{~mm}$ cells, as well as large $125 \mathrm{~mm}$ by $125 \mathrm{~mm}$ semisquare cells. It also nicely illustrates how embedding such thin and fragile cells can adequately protect them mechanically, the cell can be locally pinched without cracking, such a thing is virtually impossible to do with standalone $45-\mu \mathrm{m}$ silicon.

With long-term reliability in mind, a number of measures could already be considered. A slightly adapted flow would be to provide the outside contacts of the metallization on the glass instead of on the silicone, to avoid pressure on the metallization during contact welding, and to induce a weak point in the module. Fig. 16 schematically shows such a layer buildup for the case of the i-module flow.

In the current flow, this could be done by additional laser drilling. An even simpler approach would be to "pre-tape" the modules before coating silicones and removing the silicone in the taped areas after coating. This is illustrated in Fig. 17. However, if the tape is removed only after the silicone is cured, this results in steep sidewalls, which can pose problems for subsequent metallization in terms of step coverage. Instead, it is beneficial to remove the tape before curing, thus allowing the silicone some time to reflow.

An even better solution is to integrate the contacts in the silicone layer before metallization, this would eliminate the need for a separate contacting step where the outside contacts have to be attached to the interconnect metallization. The reason is that the typically used soldering or contact welding may induce stress-related damage, such as (micro)cracks and other effects related to a thus applied local heating and pressure in the metallization. This could result in a failure or reduced performance and/or could compromise the module's lifetime. Furthermore, this way, one step, namely the contacting step,

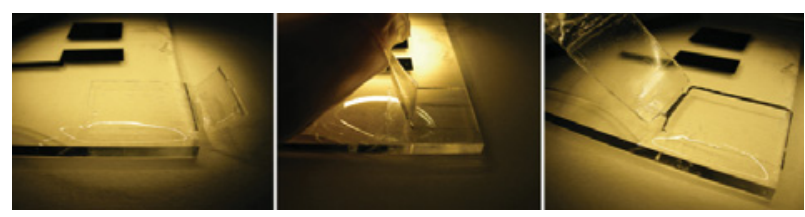

Fig. 17. Simple method to provide silicone-free areas on the glass substrate consisting of "pre-taping" those areas and removing this tape afterwards.

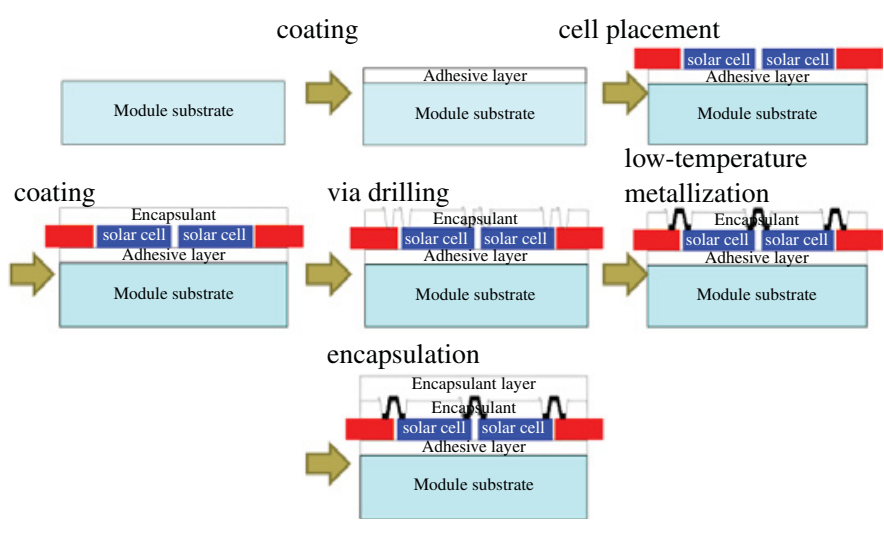

Fig. 18. Alternative flow eliminating the contacting step.

is eliminated in this kind of flow, as illustrated schematically in Fig. 18.

Finally, a few other considerations that will impact the performance and reliability of the final module still require some more attention: the backside encapsulation, with or without incorporation of a backsheet; glass coatings for antireflective and/or anti-soiling properties; and the sealing, specifically around the areas where contacts come out of the module.

\section{CONCLUSION}

In this paper, a novel concept for solar cell packaging and interconnection was introduced, together with more extensive information on how to apply standard and novel module materials and fabrication technologies to realize such a flow. The novelty of the concept can be found in the use of an alternative encapsulant (silicones as opposed to EVA), an alternative deposition technology (wet coating as opposed to dry lamination, and module-level metallization techniques (as opposed to cell-level tabbing-stringing or conductive foil interconnects), targeting improvements in performance, reliability, and cost. Furthermore, development work has been started to implement theory into practice, resulting in proof of the concept and promising initial feasibility trials. Apart from the development progress, the importance of modeling, and reliability, which are crucial for predicting the module's lifetime in different environments, is also pointed out.

An important advantage of the developed technology is its versatility, it can be used for thick and bulky cells as well as for extremely thin back-contact solar cells, whichever way they are made. In this view, the technology can offer a near-term solution for integrating current back-contact cells into modules 
while at the same time already enabling to cope with thinner cells if and when they become available on a longer term.

As a concluding remark, however, it should be clear that some areas still have to be investigated to achieve a viable and reliable technology with proven scaling capabilities for a high-throughput production environment.

\section{ACKNOWLEDGMENT}

This research was carried out at imec, Leuven, Belgium, between the groups PhotoVoltaics, Centre for MicroSystem Technologies, and REliability and MOdeling. Dow Corning is acknowledged for supplying the silicones and providing advice.

\section{REFERENCES}

[1] J. Poortmans, S. Reber, S. Gall, C. Zahedi, and J. Alonso, "European cluster on high- and intermediate temperature thin-film crystalline $\mathrm{Si}$ solar cells R\&D: Overview of running projects and underlying roadmap," in Proc. 19th Eur. Photovolt. Solar Ener. Conf., Paris, France, Jun. 2004, pp. 397-402.

[2] J. Wohlgemuth and M. Narayanan, "Large-scale PV module manufacturing using ultrathin polycrystalline silicon solar cells," Dept. Energy Laboratory, Nat. Renewable Energy Laboratory, Golden, CO, Annu. Rep. ZDO-2-30628-03, Mar. 2005.

[3] E. Van Kerschaver and G. Beaucarne, "Back-contact solar cells: A review," Prog. Photovolt.: Res. Appl., vol. 14, no. 2, pp. 107-123, Mar. 2006.

[4] D. Rose and S. Daroczi, "Development and manufacture of reliable PV modules with $>17 \%$ efficiency," in Proc. 20th Eur. Photovolt. Solar Ener. Conf., Barcelona, Spain, Jun. 2005, pp. 2670-2673.

[5] P. C. de Jong, D. W. K. Eikelboom, R. Kinderman, A. C. Tip, J. H. Bultman, M. H. H. Meuwissen, and M. A. C. J. Nieuwenhof, "Single-step laminated full-size PV modules made with back-contacted mc-Si cells and conductive adhesives," in Proc. 19th Eur. Photovolt. Solar Ener. Conf., Paris, France, 2004, pp. 1-4.

[6] C. Copetti, "Sunweb module technology: Status and way forward," presented at the Workshop MWT Solar Cell and Module Technology, Amsterdam, The Netherlands, Nov. 2010.

[7] J. M. Gee, S. E. Garrett, and W. P. Morgan, "Simplified module assembly using back-contact crystalline-silicon solar cells," in Proc. 26th IEEE Photovolt. Solar Conf., Anaheim, CA, Sep.-Oct. 1997, pp. 1085-1088.

[8] K. R. McIntosh, J. N. Cotsell, J. S. Cumpston, A. W. Norris, N. E. Powell, and B. M. Ketola, "An optical comparison of silicone and EVA encapsulants for conventional silicon PV modules: A ray-tracing study," in Proc. 34th IEEE Photovolt. Solar Conf., Philadelphia, PA, Jun. 2009, pp. $1-7$.

[9] B. Ketola, K. R. McIntosh, A. Norris, and M. K. Tomalia, "Silicones for photovoltaic encapsulation," in Proc. 23rd Eur. Photovolt. Solar Ener. Conf., Valencia, Spain, Sep. 2008, pp. 1-6.

[10] M. D. Kempe, G. J. Jorgensen, K. M. Terwilliger, T. J. McMahon, C. E. Kennedy, and T. T. Borek, "Acetic acid production and glass transition concerns with ethylene-vinyl acetate used in photovoltaic devices," Solar Ener. Mater. Solar Cells, vol. 91, no. 4, pp. 315-329, Feb. 2007.

[11] K. R. McIntosh, N. E. Powell, A. W. Norris, J. N. Cotsell, and B. M. Ketola, "The effect of damp-heat and UV aging tests on the optical properties of silicone and EVA encapsulants," Prog. Photovol.: Res. Appl., vol. 19, no. 3, pp. 294-300, May 2011.

[12] J. Govaerts, "Technology development and characterization for interconnecting driver electronic circuitry to flat-panel displays," $\mathrm{Ph} . \mathrm{D}$. thesis, Dept. Electron. Inf. Syst., Univ. Ghent, Ghent, Belgium, Jan. 2009.

[13] B. Lee, J. Z. Liu, B. Sun, C. Y. Shen, and G. C. Dai, "Thermally conductive and electrically insulating EVA composite encapsulants for solar photovoltaic (PV) cell," Exp. Poly. Lett., vol. 2, no. 5, pp. 357-363, 2008.

[14] F. Dross, A. Labat, M. A. P. Lopez, M. A. P. Lopez, R. Raudez, A. Bruce, S. Kinne, and R. Komp, "Vacuum-free, cost-effective, developingcountry-material-available solar cell encapsulation," Solar Ener. Mater. Solar Cells, vol. 90, no. 14, pp. 2159-2166, Sep. 2006.
[15] K. R. McIntosh, J. N. Cotsell, J. S. Cumpston, A. W. Norris, N. E. Powell, and B. M. Ketola, "The effect of accelerated aging tests on the optical properties of silicones and EVA encapsulants," in Proc. 24th Eur. Photovolt. Solar Ener. Conf., Hamburg, Germany, Sep. 2009, pp. $1-8$.

[16] M. D. Kempe, "Ultraviolet light test and evaluation methods for encapsulants of photovoltaic modules," Solar Ener. Mater. Solar Cells, vol. 94, no. 2, pp. 246-253, Feb. 2010.

[17] Photovoltaics World. (2009, Oct.). DuPont, Silicon Energy Make GlassGlass c-Si Modules [Online]. Available: http://www.electroiq.com/index/ display/photovoltaics-article-display/9624487907/articles/PhotovoltaicsWorld/equipment-and_materials/glass/2009/10/dupont_silicon_energy. html

[18] C. Chow, J. Bucklew, D. Miller, and T. Cleavenger, "Selective laser processing of multilayer-material," Ind. Laser Solut., vol. 24, no. 11, pp. 15-17, Nov. 2009.

[19] J. Govaerts, E. Bosman, W. Christiaens, and J. Vanfleteren, "Fine-pitch capabilities of the flat ultrathin chip packaging (UTCP) technology," IEEE Trans. Adv. Packag., vol. 33, no. 1, pp. 72-78, Feb. 2010.

[20] S. Lee, " $\mathrm{CO}_{2}$ processing at 9 microns," Ind. Laser Solut., vol. 17, no. 3 , pp. 1-4, Mar. 2002

[21] A. Skoczek, T. Sample, and E. D. Dunlop, "The results of performance measurements of field-aged crystalline silicon photovoltaic modules," Prog. Photovolt.: Res. Appl., vol. 17, no. 4, pp. 227-240, Jun. 2009.

[22] J. Robbelein, E. Van Kerschaver, N. E. Posthuma, T. Janssens, C. Gong, and J. Poortmans, "Industrial type passivation on interdigitated back junction solar cells," in Proc. 24th Eur. Photovolt. Solar Ener. Conf., Hamburg, Germany, Sep. 2009, pp. 1992-1996.

[23] M. W. P. E. Lamers, C. Tjengdrawira, M. Koppes, I. Bennett, E. E. Bende, T. P. Visser, E. Kossen, B. Brockholz, A. A. Mewe, I. G. Romijn, E. Sauar, L. Carnel, S. Julsrud, T. Naas, P. C. de Jong, and A. W. Weeber, " $17.9 \%$ back-contacted Mc-Si cellsresulting in module efficiency of 17.0\%," in Proc. 25th Eur. Photovolt. Solar Ener. Conf., Valencia, Spain, Sep. 2010, pp. 1417-1421.

Jonathan Govaerts received the Engineering degree and the Ph.D. degree in electrical engineering from Ghent University, Ghent, Belgium, in 2004 and 2009, respectively.

$\mathrm{He}$ has been working with the Interuniversity Microelectronics Center (imec), Leuven, Belgium, since 2004. First he was involved in research on the assembly and interconnection of microelectronics on and in flexible substrates at the Associated Lab Centre for Microsystems Technology, Ghent University. He shifted to the Solar Cell Technology Group within imec in 2009. His current research interests include module integration of solar cells.

Jo Robbelein received the M.Eng. degree in electrical engineering from Provinciale Industriële Hogeschool, Kortrijk, Belgium, in 2003, and the M.Sc. degree in electrical engineering from Katholieke Universiteit Leuven, Leuven, Belgium, in 2006. He is currently pursuing the Ph.D. degree in electrical engineering with the Interuniversity Microelectronics Center, Leuven.

$\mathrm{He}$ is with the Department of Electrical Engineering, Katholieke Universiteit, Leuven. His current research interests include interdigitated backcontacted silicon solar cells.

Mario Gonzalez received the M.Sc. degree in materials science from the University of Nuevo Leon, Nuevo Leon, Mexico, in 1996, and the Ph.D. degree in mechanical and materials engineering from the Ecole Centrale, Paris, France.

He joined the Interuniversity Microelectronics Center, Leuven, Belgium, as a Research Scientist. He is the author or co-author of more than 50 papers covering the areas of numerical finite element simulation, mechanical, and thermomechanical reliability analysis of packaging, microelectromechanical systems, and stretchable interconnections. 
Ivan Gordon received the Masters degree in physics and the Ph.D. degree in the field of novel magnetic materials for sensor applications from the Katholieke Universiteit Leuven, Leuven, Belgium, in 1997 and 2002, respectively.

He joined the Interuniversity Microelectronics Center, Leuven, in June 2003 in the Solar Cell Technology Group, where he is now the Head of the Thin Film Silicon Solar Cell Team after carrying out post-doctoral research for one year. He has authored and co-authored more than 90 research papers published in journals and conference proceedings. He is currently an Associate Editor in charge of thin film silicon solar cells for the international scientific journal Solar Energy Materials and Solar Cells.

Kris Baert received the Ph.D. degree from Leuven University, Leuven, Belgium, in 1990, on PECVD of thin-film c-Si.

He was with Mitsubishi Electric, Tokyo, Japan, from 1990 to 1992. In 1992, he joined the Interuniversity Microelectronics Center, Leuven, where he managed the research and development in various areas of microelectromechanical systems and integrated microsystems. Since 2008, he has been a Program Manager for Solar Cells in the SOLO department.

Ingrid De Wolf (M'05-SM'10) received the M.S. degree in physics and the Ph.D. degree in sciences, both from the Katholieke Universiteit Leuven, Leuven, Belgium.

She joined the Reliability Group of the Interuniversity Microelectronics Center (imec), Leuven, in September 1989. Here, she worked in the field of reliability physics of semiconductor devices, with special attention to mechanical stress aspects and failure analysis. Since 1999, she has been heading the Reliability and Modeling Group in imec, where her research is focused on testing, metrology, reliability, and modeling. She became a parttime Professor at the Metals and Applied Materials Engineering Department, Katholieke Universiteit Leuven, in February 2007. She has authored or coauthored several book chapters and more than 220 research papers published in international scientific journals and conference proceedings in these fields.

Dr. Wolf is a member of the Electronic Device Failure Analysis Society.
Frederick Bossuyt was born in Kortrijk, Belgium, on September 15, 1983. He received the Masters degree in electrical engineering and the Ph.D. degree in electrical engineering from Ghent University, Ghent, Belgium, in 2006 and 2011, respectively.

He has been involved in research on stretchable electronics technologies at the Center for Microsystems Technology, Ghent University, and the Interuniversity Microelectronics Center, Leuven, Belgium, since 2006.

Steven Van Put graduated from the University College Ghent (Hogeschool Gent), Ghent, Belgium, in 1999.

He has been with the Centre for Microsystem Technologies, an associated Lab of Interuniversity Microelectronics Center, Ghent University, Leuven, Belgium, since 2002. He has been involved in several projects, both national and international, as well as bilateral and multi-partner (European and national) collaborations. His current research interests include laser-based processing and related technologies for patterning and ablation of all kinds of layers for packaging, contacting, and interconnection of optical and electrical components.

Jan Vanfleteren (M'01) received the Ph.D. degree in electronic engineering from the University of Ghent, Ghent, Belgium, in 1987.

$\mathrm{He}$ is currently a Senior Engineer and Project Manager with the Centre for Microsystems Technology, Interuniversity Microelectronics Center, and Ghent University, Leuven, Belgium. In 2004, he was appointed as part time Professor at Ghent University. He has co-authored over 200 papers published in international journals and conference proceedings and has been awarded or has applied for 12 patents. His current research interests include the development of novel interconnection, assembly, and substrate technologies, especially in the field of flexible and stretchable electronics for wearable and implantable applications.

Dr. Vanfleteren is a member of the International Microelectronics and Packaging Society (IMAPS). 